\title{
Crescimento e produtividade de gergelim em Neossolo Flúvico em função de adubação orgânica e mineral ${ }^{1}$
}

\author{
Manoel Euba Neto ${ }^{2 *}$, Walter Esfrain Pereira ${ }^{3}$, Jacob Silva Souto ${ }^{4}$, Nair Helena Castro Arriel ${ }^{5}$
}

$10.1590 / 0034-737 X 201663040018$

\section{RESUMO}

Na cultura do gergelim, o rendimento médio de grãos situa-se em torno de $650 \mathrm{~kg} \mathrm{ha}^{-1}$, sendo, porém, de $1.500 \mathrm{~kg} \mathrm{ha}^{-1} \mathrm{o}$ seu potencial produtivo, com adequado programa de adubação e com disponibilidade de água. O objetivo desta pesquisa foi verificar a resposta de dois cultivares de gergelim às adubações orgânica e mineral e seus efeitos na produtividade, no crescimento final da biomassa e em alguns componentes de produção. Foi realizado um experimento, a campo, com os cultivares BRS Seda e CNPA G4, adubados com cinco fontes orgânicas, mais duas testemunhas relativas, adubadas com sulfato de amônio, em quatro repetições, totalizando 48 parcelas. O delineamento experimental foi em blocos ao acaso, com 12 tratamentos, em esquema fatorial $(5 \times 2)+2$. Submeteram-se os resultados à análise de variância, ao teste de Tukey e às análises de componentes principais e de agrupamento. Nas adubações com as fontes orgânicas, considerou-se a equivalência de $80 \mathrm{~kg}$ de N/ha. Avaliaram-se altura de planta, cápsulas por planta, diâmetro do caule, biomassa seca, sementes por cápsula, produção de sementes por planta, produtividade, entre outras. A produtividade foi afetada pelas fontes de adubação, enquanto os cultivares diferiram quanto a massa de mil sementes. Em relação às variáveis produtividade e biomassa seca, não houve diferença estatística entre os cultivares. Os cultivares de gergelim responderam de forma semelhante à adubação orgânica, em grande parte das variáveis verificadas.

Palavras-chave: Sesamum indicum, biomassa seca, componentes de rendimento, cultivares de gergelim, análise de componentes principais.

\section{ABSTRACT}

\section{Growth and productivity of sesame in entisol as a function of organic and mineral fertilization}

In sesame crop, the average grain yield is around $650 \mathrm{~kg} \mathrm{ha}^{-1}$, but its production potential is $1500 \mathrm{~kg} \mathrm{ha}^{-1}$ with an appropriate fertilization program and water availability. The objective of this research was to verify the response of two sesame cultivars to organic and mineral fertilizers and their effects on productivity, final growth of biomass and some yield components of sesame. A field experiment was conducted with the BRS Seda and CNPA G4 cultivars, fertilized with five organic sources, plus two relative controls, fertilized with ammonium sulfate, in four replications, totaling 48 plots. The experimental design was a randomized block, with 12 treatments in a factorial scheme $(5 \times 2)+2$. The results were submitted to analysis of variance, Tukey test, and analysis of principal components and clustering. In fertilizations with organic sources, the equivalence of $80 \mathrm{Kg}$ of $\mathrm{N} / \mathrm{ha}$ was considered. The following characteristics were evaluated: plant height, capsules per plant, stem diameter, dry biomass, seeds per capsule, seed yield per plant, productivity,

\footnotetext{
Recebido em 18/02/2015 e aprovado em 03/02/2016.

${ }^{1}$ Parte da tese de doutorado do primeiro autor apresentada à Universidade Federal da Paraíba. Trabalho financiado pela Universidade Estadual do Maranhão/UEMA.

${ }^{2}$ Universidade Estadual do Maranhão, Departamento de Química e Biologia, Caxias, Maranhão, Brasil. meuban@hotmail.com

${ }^{3}$ Universidade Federal da Paraíba, Departamento de Ciências Fundamentais e Sociais, Centro de Ciências Agrárias, Areia, Paraíba, Brasil. wep@cca.ufpb.br

${ }^{4}$ Universidade Federal de Campina Grande, Unidade Acadêmica de Engenharia Florestal, Centro de Saúde e Tecnologia Rural, Patos, Paraíba, Brasil. jacob_souto@uol.com.br

Embrapa Algodão, Campina Grande, PB, Brasil. Nair@cnpa.embrapa.br

* Autor para correspondência: meuban@hotmail.com
} 
among others. The nutrient sources were statistically significant for productivity, while the cultivars present significant effects for mass of a thousand seeds. In relation to productivity variables and dry biomass, there was no statistical difference among cultivars. Sesame cultivars responded similarly to organic fertilization in large part from verified variables.

Key words: Sesamum indicum, dry biomass, yield components, sesame cultivars, principal component analysis.

\section{INTRODUÇÃO}

O gergelim (Sesamum indicum L.) é uma das culturas mais antigas, cultivada ao longo dos trópicos e subtrópicos (Çaðirgan et al., 2009), uma oleaginosa importante em todo o mundo e que produz óleo de alta qualidade, inodoro e comestível, servido ainda como uma boa fonte de proteínas, vitaminas, minerais e gordura para seres humanos e animais (Çaðirgan et al., 2009; Weiss, 2000).

Como é cultivado em regiões semiáridas em todo o mundo, o potencial de produção do gergelim é muitas vezes limitado por estresse hídrico (Boureima et al., 2012) e estresse salino, entre outros. Assim, seu cultivo em variados ambientes pode afetar seu desempenho (Adebisi et al., 2005). Os baixos rendimentos, juntamente com os problemas encontrados durante a colheita de gergelim, tendem a desencorajar agricultores, levando à diminuição da área destinada ao seu cultivo. Em geral, as restrições de produção incluem pragas, doenças, infestação de plantas daninhas, baixa fertilidade do solo, cultivares de baixo rendimento e falta de prática agronômica (Jakusko \& Usman, 2013).

A cultura do gergelim é considerada esgotante, extraindo do solo, para cada $1.000 \mathrm{~kg}$ de sementes, cerca de 30 $\mathrm{kg}$ de nitrogênio (N), $40 \mathrm{~kg}$ de fósforo $(\mathrm{P})$ e $40 \mathrm{~kg}$ de potássio $(\mathrm{K})$; mas, é uma cultura que responde bem à adubação, em especial nos solos do nordeste do Brasil, onde há carência dos elementos nutricionais $\mathrm{N}$ e $\mathrm{P}$ (Beltrão et al., 1991). Várias pesquisas de adubação indicam que a aplicação de nitrogênio, fósforo e potássio aumenta razoavelmente o retorno econômico da cultura do gergelim (Jakusko \& Usman, 2013).

Em condições semiáridas, a baixa capacidade de armazenamento de água e a baixa fertilidade do solo, além do plantio de cultivares não adaptados às condições de clima e de solo e do manejo inadequado da cultura, afetam a produção. Assim, uma das formas de se aumentar a produtividade do gergelim é pelo manejo adequado da fertilidade do solo, que contribua com a resistência das plantas ao ataque de pragas e doenças. O uso de matéria orgânica como fonte de adubação é uma boa alternativa, pois mantém a fertilidade do solo e disponibiliza nutrientes necessários para atender às exigências da cultura de forma gradativa, melhora as propriedades físicas e favorece a fauna do solo (Santos et al., 2006).
O objetivo desta pesquisa foi verificar a resposta de dois cultivares de gergelim às adubações orgânica e mineral e seus efeitos na produtividade, no crescimento final da biomassa e em alguns componentes da produção do gergelim.

\section{MATERIAL E MÉTODOS}

O experimento foi realizado de maio a outubro de 2013, em propriedade rural localizada no povoado de Rosário, distante aproximadamente $15 \mathrm{~km}$ da cidade de Caxias, Maranhão, com área compreendida entre as coordenadas 455' 62" S e 4316'65" O, com altitude média de $92 \mathrm{~m}$.

O solo da área experimental é classificado como Neossolo Flúvico (Embrapa, 2006), cujos atributos químicos e físicos (Tabela 1) foram determinados conforme Embrapa(2011).

Segundo a classificação de Thornwaite, o clima da região é do tipo $\mathrm{C}_{1} \mathrm{dA}$ 'a', ou seja, clima subúmido seco, com temperatura média mensal sempre superior a $18{ }^{\circ} \mathrm{C}$, atingindo até $39^{\circ} \mathrm{C}$ nos meses mais quentes (setembro, outubro e novembro) (Maranhão, 2011), com pluviosidade média anual entre 1.300 e 1.500 mm (Brasil, 1997) e chuvas irregulares, concentrando-se nos meses de janeiro a maio.

O delineamento experimental foi em blocos ao acaso, com 12 tratamentos, em esquema fatorial $(5 \times 2)+2$, sendo cinco fontes de matéria orgânica (esterco bovino, esterco caprino, torta de algodão, torta de mamona e ausência de adubação orgânica), dois cultivares: BRS Seda e CNPA G4, mais duas testemunhas relativas, que foram adubadas com sulfato de amônio na proporção de $80 \mathrm{~kg}$ de N/ha na respectiva parcela, em quatro repetições, totalizando 48 parcelas.

A análise química do material orgânico (Tabela 2) foi determinada conforme Embrapa (2011). Para o cálculo das quantidades de fertilizantes que foram empregadas nas adubações com as fontes orgânicas, considerou-se a equivalência de $80 \mathrm{~kg}$ de N/ha (Tabela 3). E, em relação ao fósforo, $80 \mathrm{~kg}$ de $\mathrm{P}_{2} \mathrm{O}_{5} /$ ha. As fontes de $\mathrm{Ne}_{2} \mathrm{O}_{5}$ utilizadas foram o sulfato de amônio e o superfosfato simples, respectivamente.

Excetuando-se a testemunha absoluta, ou seja, o grupo controle que não recebeu nenhum tipo de adubação, todos os demais tratamentos receberam, por parcela, $80 \mathrm{~kg}$ de $\mathrm{P}_{2} \mathrm{O}_{5}$ /ha no plantio. 
Cada parcela foi constituída de 8,0 m x 3,6 m) e área útil de 8,0 m x 2,4 m. O espaçamento foi de $0,6 \mathrm{~m}$ x 0,1 m entre linhas e plantas, respectivamente totalizando 166.667 plantas/ha e 480 plantas por parcela.

No preparo da área experimental, foi realizada apenas gradagem do solo, pois já haviam sido realizados cultivos anteriores (Queiroga et al., 2011). Na sequência, a área foi demarcada com piquetes e barbantes para constituição dos blocos e parcelas. Foram abertos sulcos, nos quais se aplicaram os tratamentos.

Por ocasião da semeadura, foram utilizadas sementes de gergelim dos cultivares BRS Seda, de cor branca; e da CNPA G4, de cor creme, desenvolvidos pela Embrapa Algodão. Foram semeadas de seis a dez sementes por cova, em locais já demarcados, conforme espaçamento dos tratamentos. Aos sete dias após a emergência (DAE), foi fei- to desbaste parcial, permanecendo três plantas por cova, e, aos 14 DAE, fez-se desbaste complementar, ficando uma planta por cova.

Quanto aos tratos culturais, para o controle de espécies vegetais invasoras foram realizadas capinas manual conforme a necessidade. As irrigações, quando necessárias, em função de veranicos, foram realizadas com sistema de irrigação por aspersão convencional, segundo a necessidade hídrica da cultura.

As variáveis analisadas foram mensuradas a partir de dez plantas por parcela da área útil, selecionadas previamente, de forma aleatória, sendo determinadas de acordo com sua respectiva metodologia cerca de 90 DAE.

Efetuou-se o corte, rente ao solo, da parte aérea das plantas, quando começaram a mudar de cor (de amarelo para marrom) e os frutos mostravam-se quase totalmente

Tabela 1: Atributos químicos e físicos do solo da área experimental na camada de $0-20 \mathrm{~cm}$ de profundidade

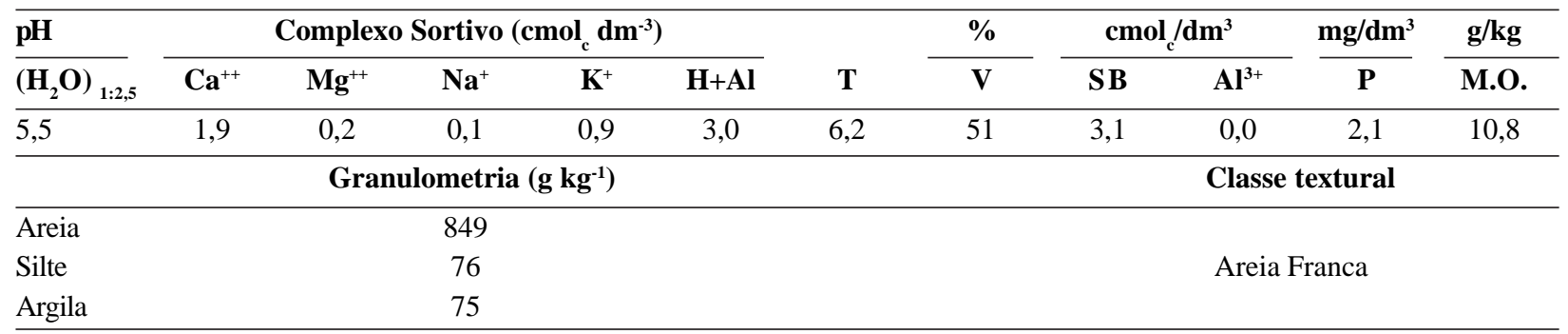

Tabela 2: Composição química da matéria seca das fontes orgânicas utilizadas no experimento

\begin{tabular}{|c|c|c|c|c|c|c|c|c|}
\hline \multirow{2}{*}{ Esterco } & $\mathbf{N}$ & $\mathbf{P}$ & $\mathbf{K}$ & $\mathbf{C a}$ & Mg & $\mathrm{C}$ & $\mathbf{S}$ & M.O. \\
\hline & \multicolumn{8}{|c|}{$\%$} \\
\hline Bovino & 1,68 & 0,07 & 0,20 & 0,09 & 0,03 & 0,55 & - & 0,95 \\
\hline Caprino & 2,11 & 0,04 & 0,08 & 0,13 & 0,09 & 3,00 & - & 5,18 \\
\hline Torta & \multicolumn{8}{|c|}{$\%$} \\
\hline Algodão & 6,77 & 1,26 & 1,13 & 0,45 & 0,40 & - & 0,22 & 86,73 \\
\hline Mamona & 4,60 & 1,20 & 0,57 & 0,83 & 0,38 & - & 0,19 & 83,80 \\
\hline
\end{tabular}

Tabela 3: Tratamentos utilizados no experimento com as variedades de gergelim

\begin{tabular}{|c|c|c|c|}
\hline Variedade & Tratamento & Fonte de adubação & Quantidade de fertilizante \\
\hline \multirow{6}{*}{ BRS Seda } & 1 & Nenhuma (testemunha absoluta) & - \\
\hline & 2 & Sulfato de amônio (SUA) (testemunha relativa) & $80 \mathrm{~kg}$ de N/ha \\
\hline & 3 & Esterco bovino (EB) & Equivalente de $80 \mathrm{~kg}$ de N/ha \\
\hline & 4 & Esterco caprino (EC) & Equivalente de $80 \mathrm{~kg}$ de N/ha \\
\hline & 5 & Torta de mamona (TM) & Equivalente de $80 \mathrm{~kg}$ de N/ha \\
\hline & 6 & Torta de algodão (TA) & Equivalente de $80 \mathrm{~kg}$ de N/ha \\
\hline \multirow{6}{*}{ CNPA G4 } & 7 & Nenhuma (testemunha absoluta) & -- \\
\hline & 8 & Sulfato de amônio (SUA) (testemunha relativa) & $80 \mathrm{~kg}$ de N/ha \\
\hline & 9 & Esterco bovino (EB) & Equivalente de $80 \mathrm{~kg}$ de N/ha \\
\hline & 10 & Esterco Caprino (EC) & Equivalente de $80 \mathrm{~kg}$ de N/ha \\
\hline & 11 & Torta de mamona (TM) & Equivalente de $80 \mathrm{~kg}$ de N/ha \\
\hline & 12 & Torta de algodão (TA) & Equivalente de $80 \mathrm{~kg}$ de N/ha \\
\hline
\end{tabular}


marrons, iniciando o processo de abertura (deiscência); em seguida, os frutos foram submetidos a uma pré-secagem ao sol.

Em relação aos componentes de produção, foi realizada a contagem de todas as cápsulas por axila foliar e por planta, e do número de sementes por cápsula, nas plantas previamente sorteadas em cada parcela. Foi pesada a massa de 1000 sementes por planta, em balança analítica de 0,0001 de precisão, previamente secadas em estufa, a 105 ${ }^{\circ} \mathrm{C}$, durante 24 horas, utilizando-se três amostras por repetição (Queiroga \& Beltrão, 2001).

A produtividade $\left(\mathrm{kg} \mathrm{ha}^{-1}\right)$ e a produção de sementes $(\mathrm{kg})$ foram estimadas ao final do ciclo cultural, com a colheita das plantas da área útil. Posteriormente, as medas foram batidas, sobre uma superfície recoberta com plástico, para liberar as sementes, que foram guardadas em sacos de papel, devidamente identificados e, depois, pesadas. Para o cálculo da produtividade, dividiu-se a massa das sementes (g/planta) pela densidade final de plantas $/ \mathrm{ha}^{-1}$ da área útil de cada parcela e o valor, obtido em $\mathrm{kg} \mathrm{parcela}^{-1}$, foi transformado para $\mathrm{kg} \mathrm{ha}^{-1}$.

Os resultados foram submetidos à análise de variância e de correlação de Pearson. As médias das fontes de adubação foram comparadas pelo teste de Tukey, a 5\% de probabilidade. As variedades e os tratamentos adicionais foram submetidos ao teste F. Por causa da heterogeneidade das variâncias, os dados da produção de sementes por planta foram transformados para $\ln (\mathrm{y})$. Posteriormente, realizaram-se análises de componentes principais e de agrupamento. As análises estatísticas foram realizadas com o software SAS 9.2 (2011).

\section{RESULTADOS E DISCUSSÃO}

Os efeitos das fontes de adubação foram estatisticamente significativos apenas para o número de sementes por planta (NSP) e para a produtividade, enquanto os cultivares apresentaram diferenças significativas quanto a massa de 1000 sementes (MMS) e NSP(Tabela 4). Em relação à produção de sementes por planta (PrdSP) e ao efeito de interação entre fontes de adubação e cultivares, não houve significância.

Particularizando-se as adubações orgânicas à base de estercos bovino e caprino, observaram-se valores experimentais para a PrdSP iguais a 29,32 e 21,32 g, respectivamente, enquanto Haruna \& Abimiku (2012), em experimento com adubação orgânica, obtiveram produção de sementes por planta iguais a 13,99 e 13,27 g, respectivamente, na média de dois anos.

Conforme os resultados obtidos entre os tratamentos, a aplicação de adubos orgânico ou mineral não influenciou a MMS dos dois cultivares de gergelim em estudo (Tabela 4). Resultados divergentes foram observados por Bhatti et al. (2005); Haruna \& Abimiku (2012); Grilo Júnior \& Azevedo (2013), com médias iguais a 3,62; 3,47 e 3,45 g, respectivamente, valores superiores em 12,98, 10,16 e 9,52\% aos desta pesquisa $(3,15)$, considerando-se o esterco bovino (Figura 1). No entanto, resultado inferior e igual a 2,31 foi encontrado por Jakusko \& Usman (2013) e estes fatos podem ser devidos a temperaturas elevadas, em torno de $40{ }^{\circ} \mathrm{C}$, causando abortamento de flores e o não enchimento dos frutos, além de redução do número de frutos por planta (Beltrão et al., 2001). Também, a disponibilidade de $\mathrm{N}, \mathrm{P}$ e K do solo pode ter sido baixa, influenciando de forma negativa o desenvolvimento da semente.

Resultados também divergentes para MMS foram observados por Mesquita et al. (2013) e resultados iguais ao desta pesquisa, para o NSP, e inferiores, para MMS, foram observados em genótipos de gergelim nigerianos, avaliados por Adebisi et al. (2005), enquanto Menzir (2012), trabalhando com genótipos da Etiópia, verificou resultados semelhantes, para massa de mil sementes, e divergentes, em relação à produtividade de sementes/ha. Contudo, os valores experimentais, obtidos e iguais a $2,31 \mathrm{~g} \mathrm{e} 0,51 \mathrm{t} / \mathrm{ha}$, são inferiores à média geral, entre os tratamentos, de 3,09 g (Figura 1) e 1,16 t/ha alcançados nesta pesquisa (Figura 2B). As diferenças podem ser atribuídas a condições de solo (reação, matéria orgânica, textura do solo), altitude, clima, entre outros.

Tabela 4: Valores de quadrado médio e coeficiente de variação (C.V. \%) da massa de mil sementes, número de sementes por planta, produção de sementes por planta e produtividade na cultura do gergelim.

\begin{tabular}{lccccc}
\hline \multirow{2}{*}{ Fontes de variação } & GL & \multicolumn{4}{c}{ Variáveis } \\
\cline { 3 - 5 } & & MMS & NSP & PrdSP & Produtividade \\
\hline Blocos & 3 & $0,4448^{* *}$ & $11.306 .633,3^{\text {ns }}$ & $0,2286^{\mathrm{ns}}$ & $0,3452^{* *}$ \\
Fontes (F) & 5 & $0,0213^{\text {ns }}$ & $35.385 .612,5^{* *}$ & $0,3546^{\mathrm{ns}}$ & $0,1984^{*}$ \\
Cultivar (C) & 1 & $1,4260^{* *}$ & $59457127,9^{*}$ & $0,0575^{\mathrm{ns}}$ & $0,0242^{\mathrm{ns}}$ \\
F x C & 5 & $0,1967^{\mathrm{ns}}$ & $6970553,9^{\text {ns }}$ & $0,1515^{\mathrm{ns}}$ & $0,0490^{\mathrm{ns}}$ \\
Resíduo & 33 & 0,0974 & $9.167 .964,00$ & 0,1551 & 0,0626 \\
Total & 47 & & & & 21,58 \\
\hline CV \% & & 10,09 & 26,30 & 13,67 & \\
\hline
\end{tabular}

ns, *, **: não significativo, significativo a 5 e $1 \%$ pelo teste $\mathrm{F}$, respectivamente. 
As fontes de adubação esterco bovino e torta de algodão, estatisticamente iguais, proporcionaram o maior número de sementes por planta. O tratamento testemunha foi o que apresentou o menor número de sementes por planta, diferindo do esterco bovino e da torta de algodão (Figura 2A). A razão para esta diferença, entre outras, pode ser o fato de estas fontes orgânicas apresentarem, por exemplo, maiores teores de fósforo e de potássio.

O esterco caprino proporcionou a maior produtividade em toneladas de grãos por hectare, porém não diferentemente das outras fontes testadas, enquanto a testemunha foi a que apresentou a menor produtividade (Figura 2B). Mesquita et al. (2013), em cultivo irrigado com o cultivar BRS Seda, alcançaram produtividades variando de 0,26 a 1,01 t ha ${ }^{-1}$; enquanto Grilo Júnior \& Azevedo (2013), em condições semelhantes e com o mesmo cultivar, obtiveram 1,60 t ha ${ }^{-1}$. Avaliando características agronômicas de gergelim, Bhatti et al. (2005) obtiveram produtividade de grãos com o máximo rendimento de $0,74 \mathrm{tha}^{-1}$, valor inferior aos de todos os tratamentos utilizados nesta pesquisa, inclusive, ao da testemunha absoluta (Figura 2B). As dife-

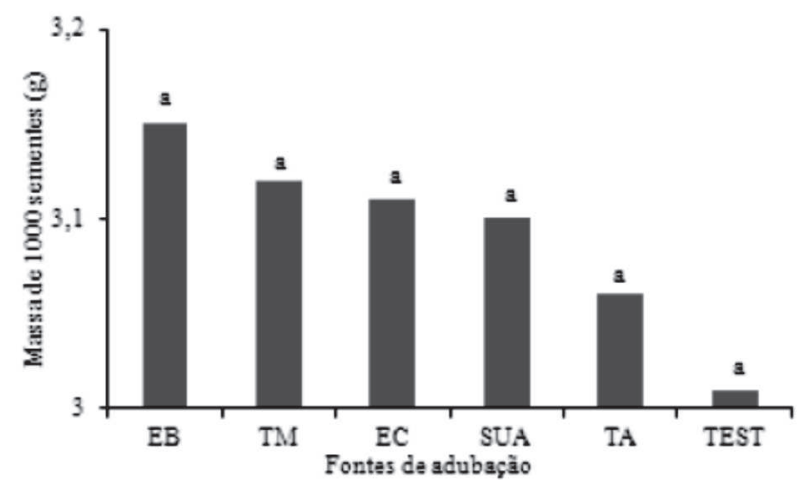

Figura 1: Massa de mil sementes de gergelim em função da fonte de adubação. Médias ( $\mathrm{n}=8)$ seguidas de mesma letra não diferem entre si pelo teste de Tukey a 5\% de probabilidade. $\mathrm{EB}=$ esterco bovino; $\mathrm{EC}=$ esterco caprino; $\mathrm{TA}=$ torta de algodão; $\mathrm{TM}=$ torta de mamona; SUA = sulfato de amônio; TEST = testemunha. renças observadas nos resultados das pesquisas são inicialmente devidas à diversidade de situações dos locais de pesquisa. No entanto, as condições ambientais podem ter influenciado as plantas, em algum momento do ciclo, a direcionar energia para o crescimento vegetativo, em vez de realizar a translocação de nutrientes para o enchimento dos grãos.

A análise pelo método dos componentes principais, aplicada à matriz de correlação das características de crescimento, produção e produtividade, permitiu identificar dois autovalores, CP1 (7,281) e CP2 (5,378). Logo, para interpretação dos resultados, optou-se por utilizar os dois componentes, levando-se em consideração que estes tenham captado uma proporção significativa de $66,62 \%$ da variância total das variáveis originais. O primeiro componente (CP1), pode explicar individualmente a maior parcela da variância, captou $38,32 \%$ da variância e o segundo componente (CP2) captou $28,30 \%$. Resultados semelhantes foram obtidos por Parsaeian et al. (2011) e por Furat \& Uzun (2010), cujos componentes explicaram 67,29 e 69,9\% da variação total, respectivamente.

$\mathrm{Na}$ interpretação de cada um dos componentes consideraram-se valores absolutos superiores a 0,25 e 0,26 para os autovetores dos componentes 1 e 2 , respectivamente (Tabela 5). Percebe-se que o primeiro componente principal está positivo e fortemente correlacionado com as variáveis número de folhas por planta (NFP), número de galhos por planta (NGP), número de frutos por planta (NFrP), número de sementes por fruto (NSFr), número de sementes por planta (NSP), massa seca foliar (MSF), massa seca do caule (MSC), massa seca do fruto (MSFr), massa seca da raiz (MSR) e produção de sementes por planta (PrdSP), que expressam as variáveis agronômicas relacionadas com o crescimento e com os componentes de produção agrícola do gergelim, nas condições experimentais, as quais tiveram a maior contribuição à diversidade total e foram as responsáveis pela diferenciação dos quatro grupos. Os
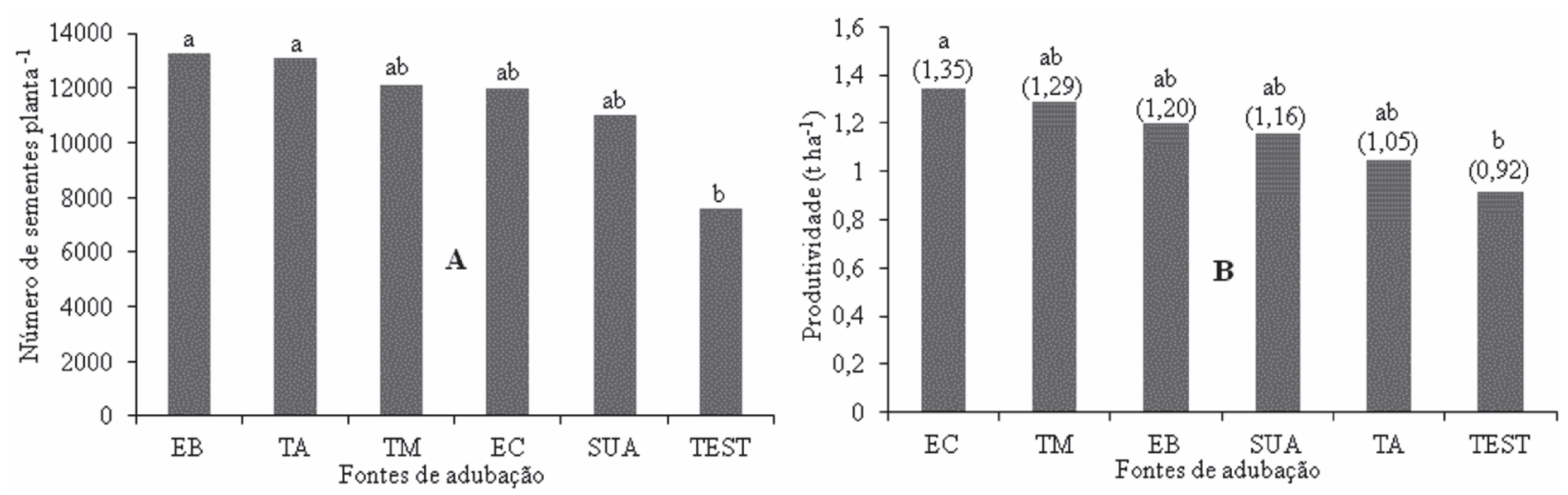

Figura 2: Número de sementes por planta e produtividade de gergelim em função da fonte de adubação. Médias $(\mathrm{n}=8)$ seguidas de mesma letra não diferem entre si pelo teste de Tukey a 5\% de probabilidade. $\mathrm{EB}=$ esterco bovino; $\mathrm{EC}=$ esterco caprino; $\mathrm{TA}=$ torta de algodão; TM = torta de mamona; SUA = sulfato de amônio; TEST = testemunha. 
caracteres com maiores valores absolutos e mais próximos da unidade influenciam os componentes do grupo mais do que aqueles com menores valores absolutos e mais próximos de zero (Chahal \& Gosal, 2002). Os resultados estão

Tabela 5: Autovetores dos componentes principais, CP1 e CP2, relativos aos valores das características de crescimento, dos componentes de produção, produção e produtividade

\begin{tabular}{lrr}
\hline Variáveis & CP1 & CP2 \\
\hline Número de folhas por planta & $\mathbf{0 , 2 9 3}$ & $-0,199$ \\
Número de galhos por planta & $\mathbf{0 , 2 5 0}$ & $-0,252$ \\
Altura do primeiro fruto & $-0,049$ & $\mathbf{0 , 3 3 6}$ \\
Número de frutos por planta & $\mathbf{0 , 3 4 4}$ & $-0,081$ \\
Número de sementes por fruto & $\mathbf{0 , 2 5 1}$ & 0,106 \\
Número de sementes por planta & $\mathbf{0 , 3 5 4}$ & $-0,072$ \\
Matéria seca foliar & $\mathbf{0 , 2 5 9}$ & 0,046 \\
Matéria seca do caule & $\mathbf{0 , 2 9 9}$ & 0,162 \\
Matéria seca do fruto & $\mathbf{0 , 3 3 4}$ & 0,071 \\
Matéria seca da raiz & $\mathbf{0 , 3 3 2}$ & 0,081 \\
Massa de cem sementes & 0,003 & $\mathbf{0 , 3 7 2}$ \\
Massa de mil sementes & 0,003 & $\mathbf{0 , 3 7 3}$ \\
Produtividade (kg ha $\left.{ }^{-1)}\right)$ & 0,195 & $\mathbf{0 , 2 6 8}$ \\
Produção por parcela útil $(\mathrm{kg})$ & 0,194 & $\mathbf{0 , 2 6 2}$ \\
Produção de sementes por planta & $\mathbf{0 , 2 6 3}$ & $-0,002$ \\
TRCA & $-0,033$ & $\mathbf{0 , 3 3 0}$ \\
TRCD & 0,097 & $-0,195$ \\
ALT90 & $-0,093$ & $\mathbf{0 , 2 6 3}$ \\
DIAM90 & $-0,012$ & $\mathbf{- 0 , 2 9 5}$ \\
\hline
\end{tabular}

TRCA = Taxa relativa de crescimento em altura; TRCD = Taxa relativa de crescimento em diâmetro; ALT90 = Altura aos 90 dias após emergência; DIAM90 = Diâmetro do caule aos 90 dias após emergência. de acordo com os constatados por Akbar et al. (2011), no que se refere ao NRP, NFrP, NSFr e à produção de sementes por planta (PrdSP).

A altura do primeiro fruto (AltFr), a massa de 100 sementes (MCS), a massa de 1000 sementes (MMS), a produtividade $\left(\mathrm{kg} \mathrm{ha}^{-1)}\right)$, a produção por parcela útil $(\mathrm{kg})$, a taxa relativa de crescimento em altura (TRCA) e a altura final aos 90 DAE (ALT90) contribuíram muito para o segundo componente principal, sendo que MMS, MCS e AltFr foram as características que melhor explicaram o componente principal 2, com escores da ordem de 0,$373 ; 0,372$ e 0,336 , respectivamente.

Resultados semelhantes, com genótipos de gergelim, foram encontrados por Tripathi et al. (2014), para as características número de ramos por planta, produção de sementes por planta e altura de planta, e, por Menzir (2012), para NFrP, produtividade $\left(\mathrm{kg} \mathrm{ha}^{-1)}\right)$, produção por parcela útil (kg), MMS (g), ALT90 (cm) e NRP, indicando que estas características estão relacionadas com plantas com alta produção de sementes, tendo Tripathi et al. (2014) encontrado resultados discordantes dos desta pesquisa, com relação a massa de 1000 sementes.

Com base nos escores do primeiro e do segundo componentes principais, foi possível identificar quatro grupos de tratamentos (Figura 3). Os resultados desta pesquisa estão de acordo com os obtidos por Akbar et al. (2011), que utilizam em seu estudo características agromorfológicas como base para o agrupamento.

No grupo 1, do cultivar BRS Seda, pode ser verificado que os tratamentos testemunha (T), esterco bovino (EB), esterco caprino (EC), torta de algodão (TA) e sulfato de

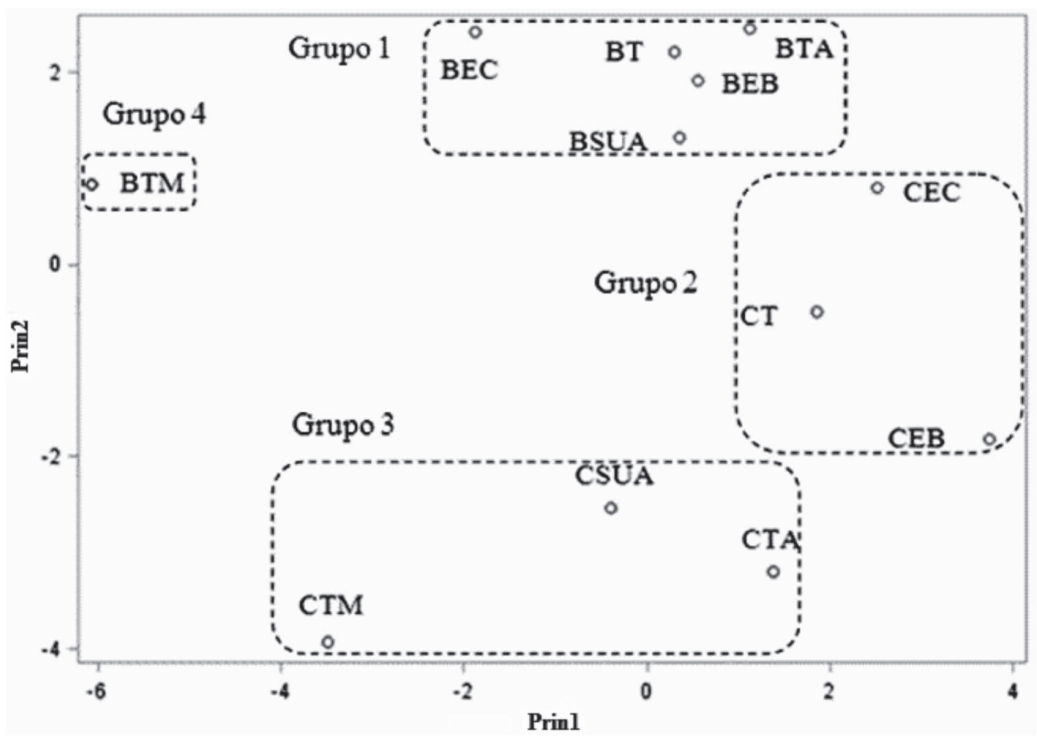

Figura 3: Agrupamento dos tratamentos com base nos escores do primeiro e do segundo componente principal, Prin1 e Prin2, do experimento com a cultura de gergelim. Médias $(n=12)$ doze repetições. BRS Seda $(B E C=$ esterco caprino; BEB = esterco bovino; $\mathrm{BT}=$ testemunha; $\mathrm{BTA}=$ torta de algodão; $\mathrm{BTM}=$ torta de mamona; $\mathrm{BSUA}=$ sulfato de amônio); $\mathrm{CNPA}$ G4 $(\mathrm{CEC}=$ esterco caprino; $\mathrm{CEB}=$ esterco bovino; $\mathrm{CT}=$ testemunha; $\mathrm{CTA}=$ torta de algodão; $\mathrm{CTM}=$ torta de mamona; $\mathrm{CSUA}=$ sulfato de amônio). 
amônio (SUA) apresentam os maiores valores das variáveis relacionadas com o segundo componente principal, ou seja, MMS, MCS e AltFr. O grupo 2, relativo ao cultivar CNPA G4, constituído pelos tratamentos testemunha (T), esterco bovino (EB) e esterco caprino (EC), apresentou os maiores valores para as variáveis relacionadas com o primeiro componente principal (Figura 3).

Já o grupo 3, que contempla ao cultivar CNPA G4, apresentou semelhança entre os tratamentos TM, SUA e TA, e teve os menores escores no segundo componente principal. De forma isolada, formando o grupo 4, aparece o tratamento torta de mamona (TM) no cultivo da BRS Seda, com os menores escores no primeiro componente principal (Figura 3).

A diferenciação dos genótipos em diferentes grupos deve-se a efeito cumulativo de um número grande de caracteres, em vez da contribuição de poucos caracteres específicos ( $\pm 0,250$ - 0,373), de menor e maior contribuição entre os componentes principais (Menzir, 2012). Resultados semelhantes quanto à formação de grupos foram obtidos por Parsaeian et al. (2011).

Com base na classificação conjunta dos escores do primeiro e do segundo componentes principais, pode-se verificar que, considerando-se todos os tratamentos desta pesquisa, o tratamento TM foi o de menor desempenho em relação às características de crescimento, produção e produtividade em estudo e, de forma oposta, o tratamento TA foi o de maior desempenho. Talvez, por razões de natureza ambiental, as plantas da variedade CNPA G4, cultivadas no tratamento com torta de mamona, tenham gastado mais energia na produção de biomassa.

\section{CONCLUSÕES}

As variedades de gergelim responderam de forma semelhante à adubação orgânica, em grande parte das variáveis de crescimento e de produção verificadas.

A produção, a massa de mil sementes, seguidas pela massa seca da cápsula, pelo número de sementes por planta e pelo número de cápsula por planta, constituem-se nas variáveis que melhor evidenciam o potencial produtivo das variedades de gergelim estudadas.

Nas condições deste experimento, o esterco caprino pode ser recomendável para o cultivo das variedades de gergelim BRS Seda e CNPA G4, por terem seus resultados diferido dos da testemunha.

\section{AGRADECIMENTOS}

Os autores agradecem à Universidade Estadual do Maranhão (UEMA), pela liberação e concessão da bolsa e à Embrapa Algodão, pelas sementes e análises laboratoriais.

\section{REFERÊNCIAS}

Adebisi MA, Ajala MO, Ojo DK \& Salau AW (2005) Influence of population density and season on seed yield and its components in Nigerian sesame genotypes. Journal of Tropical Agriculture, 43:13-18.

Akbar F, Rabbani AM, Shinwari ZK \& Khan SJ (2011) Genetic divergence in sesame (Sesamum indicum L.) landraces based on qualitative and quantitative traits. Pakistan Journal Botany, 43:2737-2744.

Beltrão NEM, Souza JG, Amorim Neto MS \& Araújo AE (2001) Ecofisiologia e Fisiologia. In: Beltrão NEM \& Vieira DJ (Eds.) O agronegócio do gergelim no Brasil. Brasília, Embrapa Informação Técnica. 348p.

Beltrão NEM, Vieira DJ, Nóbrega LB \& Santos JW (1991) Adubação, cultivar e controle de plantas daninhas na cultura do gergelim. Pesquisa Agropecuária Brasileira, 26:605-611.

Boureima S, Oukarroumb A, Dioufa M, Cissea N \& Damme PV (2012) Screening for drought tolerance in mutant germplasm of sesame (Sesamum indicum) probing by chlorophyll a fluorescence. Environmental and Experimental Botany, 81:37-43.

Bhatti IH, Ahmad R \& Nazir MS (2005) Agronomic traits of sesame as affected by grain legumes intercropping and planting patterns. Pakistan Journal Agriculture Science, 42:56-60.

BRASIL (1997) Zoneamento Geoambiental do Estado do Maranhão: Diretrizes gerais para a ordenação territorial. Salvador, Bahia. 44p.

Çaðirgan MI, Özerden S \& Özba ${ }^{\circ}$ MO (2009) Agronomic trait assessment and selection for number of capsules in determinate $\mathrm{x}$ indeterminate crosses of sesame. Turkish Journal of Agriculture and Forestry, 33:231-241.

Chahal GS \& Gosal SS (2002) Principles and procedures of plant breeding: biotechnology and conventional approaches. Narosa Publishing House, New Delhi. 604p.

EMBRAPA - Empresa Brasileira de Pesquisa Agropecuária (2011) Donagema GK, Campos DVB, Calderano SB, Teixeira WG \& Viana JHM (Eds.) Manual de métodos de análise de solos. Rio de Janeiro, Embrapa Solos. 230p.

EMBRAPA - Empresa Brasileira de Pesquisa Agropecuária (2006) Sistema Brasileiro de Classificação de Solos. Rio de Janeiro, Embrapa/CNPS. 2 ${ }^{\mathrm{a}}$ ed. 306p.

Furat S \& Uzun B (2010) The use of agro-morphological characters for the assessment of genetic diversity in sesame (Sesamum indicum L.). Plant Omics Journal, 3:85-91.

Grilo Júnior JAS \& Azevedo PV (2013) Crescimento, desenvolvimento e produtividade do gergelim BRS Seda na agrovila de Canudos, em Ceará Mirim (RN). Holos, 2:19-33.

Haruna IM \& Abimiku MS (2012) Yield of Sesame (Sesamum indicum L.) as influenced by organic fertilizers in the Southern Guinea Savanna of Nigeria. Sustainable Agriculture Research, 1:66-69.

Jakusko BB \& Usman BD (2013) Effects of NPK fertilizer and plant population density on productivity of sesame (Sesamum indicum L.). Research Journal of Agricultural and Environmental Management, 2:121-126.

Maranhão (Estado) Secretaria de Estado do Meio Ambiente e Recursos Naturais (2011) Plano de ação para prevenção e controle do desmatamento e das queimadas no estado do Maranhão. São Luis, Maranhão. 110p.

Menzir A (2012) Phenotypic variability, divergence analysis and heritability of characters in sesame (Sesamum indicum L.) genotypes. Nature and Science, 10:117-126. 
Mesquita JBR, Azevedo BM, Campelo AR, Fernandes CNV \& Viana TVA (2013) Crescimento e produtividade da cultura do gergelim (Sesamum indicum L.) sob diferentes níveis de irrigação. Irriga, 18:364-375.

Parsaeian M, Mirlohi A \& Saeidi G (2011) Study of genetic variation in Sesame (Sesamum indicum L.) using agro-morphological traits and ISSR markers. Russian Journal of Genetics, 47:314321 .

Queiroga VP, Gondim TMS, Vale DG, Gereon HGM \& Queiroga DAN (2011) Produção de gergelim orgânico em agricultura familiar no Nordeste brasileiro. Revista Agroambiente On-line, 5:166-172.

Queiroga VP \& Beltrão NEM (2001) Produção de sementes. In: Beltrão NEM \& Vieira DJ (Eds.) O Agronegócio do gergelim no Brasil. Brasília, Embrapa Algodão. p.285-301.
Santos JF, Oliveira AP, Alves AU, Brito CH, Dornelas CSM \& Nóbrega JPR (2006) Produção de batata-doce adubada com esterco bovino em solo com baixo teor de matéria orgânica. Horticultura Brasileira, 24:103-106.

SAS Institute Inc. (2011) Statistical Analysis System user's guide. Version 9.3. Cary, Statistical Analysis System Institute. $8621 \mathrm{p}$.

Tripathi A, Bisen R, Ahirwal RP, Paroha S, Sahu R \& Ranganatha ARG (2014) Study on genetic divergence in sesame (Sesamum indicum L.) germplasm based on morphological and quality traits. The Bioscan, 8:1387-1391.

Weiss EA (2000) Oilseed Crops. $2^{\mathrm{a}}$ ed. United Kingdom, Blackwell Science LTD. $355 \mathrm{p}$ 